\title{
Thyrolipoma: A Rare Thyroid Gland Entity
}

\author{
Singh $\mathbf{P}^{1}$, Mittal MK ${ }^{2}$, Sharma $\mathbf{S}^{3}$ \\ ${ }^{1}$ Department of Radiodiagnosis and Imaging, Aryan Multi Speciality Hospital, Gurgaon, \\ Haryana, India \\ ${ }^{2}$ Department of Radiodiagnosis and Imaging, Vardhman Mahavir Medical College and \\ Safdarjung Hospital, New Delhi, India \\ ${ }^{3}$ Department of Pathology, Kalpana Chawla Government Medical College, Karnal, \\ Haryana, India
}

Received: April 25, 2019

Accepted: May 25, 2019

Published: June 30, 2019

Cite this paper:

Singh P, Mittal MK, Sharma S. Thyrolipoma: A Rare Thyroid Gland Entity. Nepalese Journal of Radiology 2019;9(13):24-29.https://doi.org/10.3126/njr.v9i1.24813

\begin{abstract}
Fat-containing thyroid swellings are rare with limited differentials including lipomatous goiter, heterotopic thyroid rests, amyloid goiter, lymphocytic thyroiditis, Grave's disease, adenolipoma, intrathyroid thymic or parathyroid lipoma, encapsulated papillary carcinoma, and liposarcoma etc. We present a case of a 60 -year-old euthyroid female with a long standing thyroid swelling radiologically and pathologically diagnosed as thyrolipoma (adenolipoma). Thyrolipomas are occasionally diagnosed. However, these lesions are considered to be benign and are treated surgically.
\end{abstract}

Keywords: Mature Macroscopic Fat; Thyrolipoma; Thyroid Gland

Correspondence to: Dr. Sonam Sharma

Assistant Professor

Department of Pathology

Kalpana Chawla Government Medical College

Karnal, Haryana, India

Email: drsonamsharma@gmail.com

\section{INTRODUCTION}

Fat containing lesions of the thyroid gland are very rare with only a few cases described in the literature. Nodules of the thyroid gland that contain macroscopic fat are usually benign and have an important therapeutic as well as prognostic implication. Thyrolipoma is a biologically inactive encapsulated neoplasm which is composed of thyroid gland tissue and fat in different proportions. ${ }^{1}$ Its diagnosis is challenging because of its rarity and diversity of fat-containing thyroid lesions. Nevertheless, once it is accurately diagnosed by various modalities, the treatment of choice for it is surgical resection and the prognosis 
is favorable. We describe one such rare case of thyrolipoma in an elderly female which created a diagnostic conundrum and discuss briefly the approach as well as differential diagnosis of fat-containing thyroid lesions, with emphasis on the role of radiology and cytology in such a scenario.

\section{CASE REPORT}

A 60-year-old female presented to the surgical outpatient department of the hospital with the chief complaints of gradually increasing midline neck swelling since last 4 years with a recent history of mild difficulty in breathing since last 5 months. There was no history of palpitation, tremor or sweating. Her medical history was significant as she was a diabetic. On physical examination, pallor was evident. No icterus or lymphadenopathy was detected. The clinical examination of the swelling revealed an enlarged soft lobulated thyroid gland which moved on deglutition. The swelling was extending from the level of angle of mandible to the suprasternal notch and was more prominent on the right side. A clinical diagnosis of multinodular colloid goiter was made. Laboratory findings confirmed the euthyroid state. The patient was referred for an ultrasound (USG) neck. Sonographic scan of the neck (Figure 1a, 1b and 1c) showed grossly enlarged thyroid gland lobes with multiple echogenic lobules within the gland with multiple intervening hypoechoic linear areas. On Doppler evaluation (Figure 1d), moderate vascularity was seen within these hypoechoic areas. No significant lymphadenopathy was present. On the basis of echogenic nature of the lesion, it was diagnosed as goiter with multiple benign nodules. Contrast-enhanced computed tomography (CECT) scan was done to know the exact extent of the lesion. Plain CT (Figure 2a) revealed enlarged thyroid gland (right lobe $>$ left lobe) with a lesion of fat attenuation. CECT (Figure 2b and $2 \mathrm{c}$ ) showed well defined fat attenuated intra-thyroid lesion measuring about $8.8 \times 7.5$ $\mathrm{x} 5.1 \mathrm{~cm}$ with areas of linear enhancement. Thick rim of thyroid parenchyma was seen surrounding the lesion. At the level of lower cervical region the enlarged thyroid gland was seen mildly compressing the trachea (transverse diameter reduced). Inferiorly the lesion extended upto the level of sternal notch. The planes with the adjacent structures were maintained. No significant cervical or mediastinal lymphadenopathy was seen.

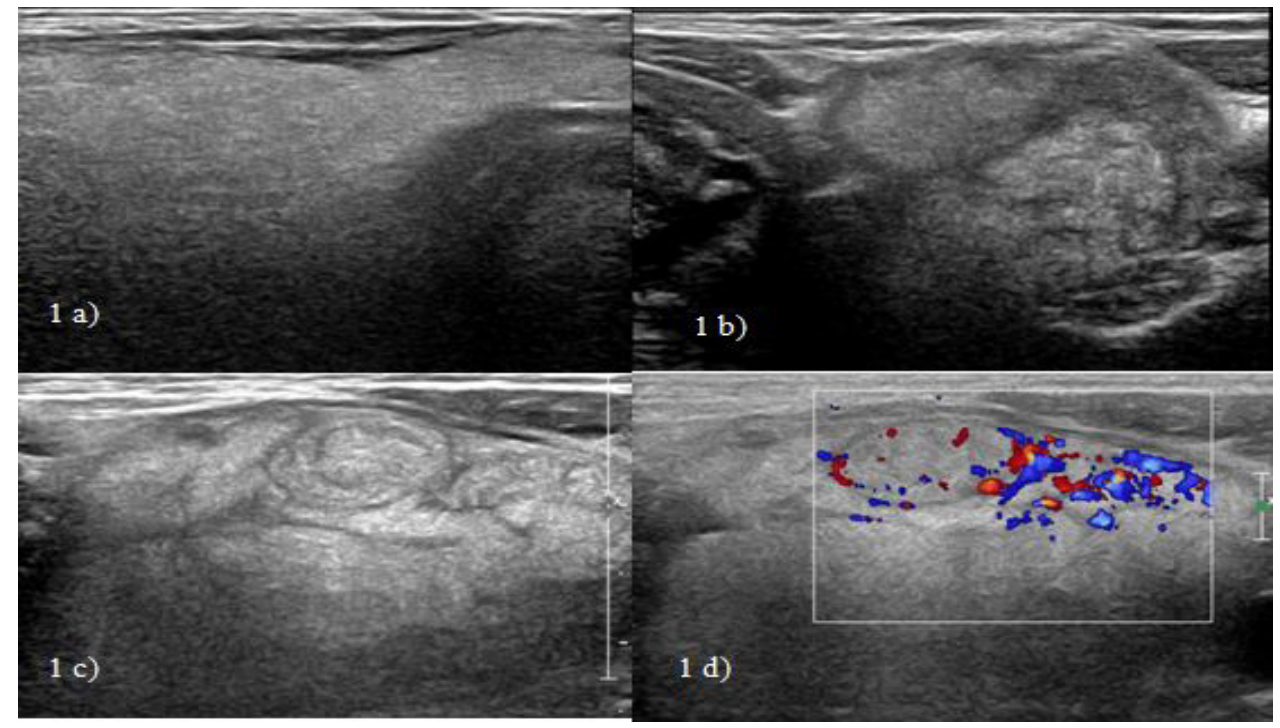

Figure 1: Sonograhic scan of neck. 1a. Transverse ultrasound image of neck shows diffusely echogenic and enlarged thyroid lobes. 1 b. \& 1c. shows echogenic lobules within the enlarged thyroid lobes. 1 d. Doppler examination showed peripheral color uptake within the echogenic lobules. 


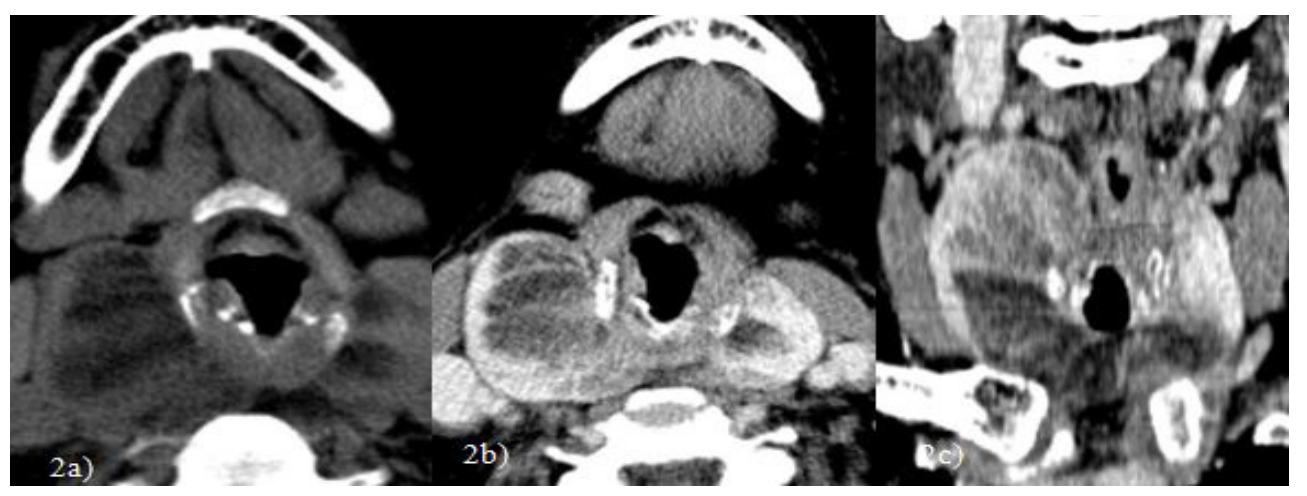

Figure 2: CT scan of neck. Non-enhanced transverse CT scans 2a. through the lower neck shows a well-circumscribed, predominantly fatty mass (Hounsfield units -30HU) of the thyroid gland. The mass causes enlargement of the isthmus and extends to both right and left lobes. $2 \boldsymbol{b} . \mathbf{\&} 2 \boldsymbol{2}$. CECT neck shows the fatty lesion extending upto the superior mediastinum with areas of linear enhancement within.

The presence of fat in a patient clinically diagnosed as multinodular goiter added to the diagnostic dilemma. Magnetic Resonance Imaging (MRI) was done to confirm the fatty nature of the lesion. MRI showed the thyroid lesion with similar extent as described on CT with preserved adjacent fat planes. The intra-thyroid lesion was hyperintense on both
T1W and T2W (Figure 3a, 3b and 3c) images. Suppression of hyperintensity seen on T1W fat-saturated (Figure 3d) and STIR (Short Ti Inversion Recovery) images confirming the fatty nature. Based on the macroscopic fat containing intra-thyroid lesion, a diagnostic possibility of thyrolipoma (adenolipoma) was kept.

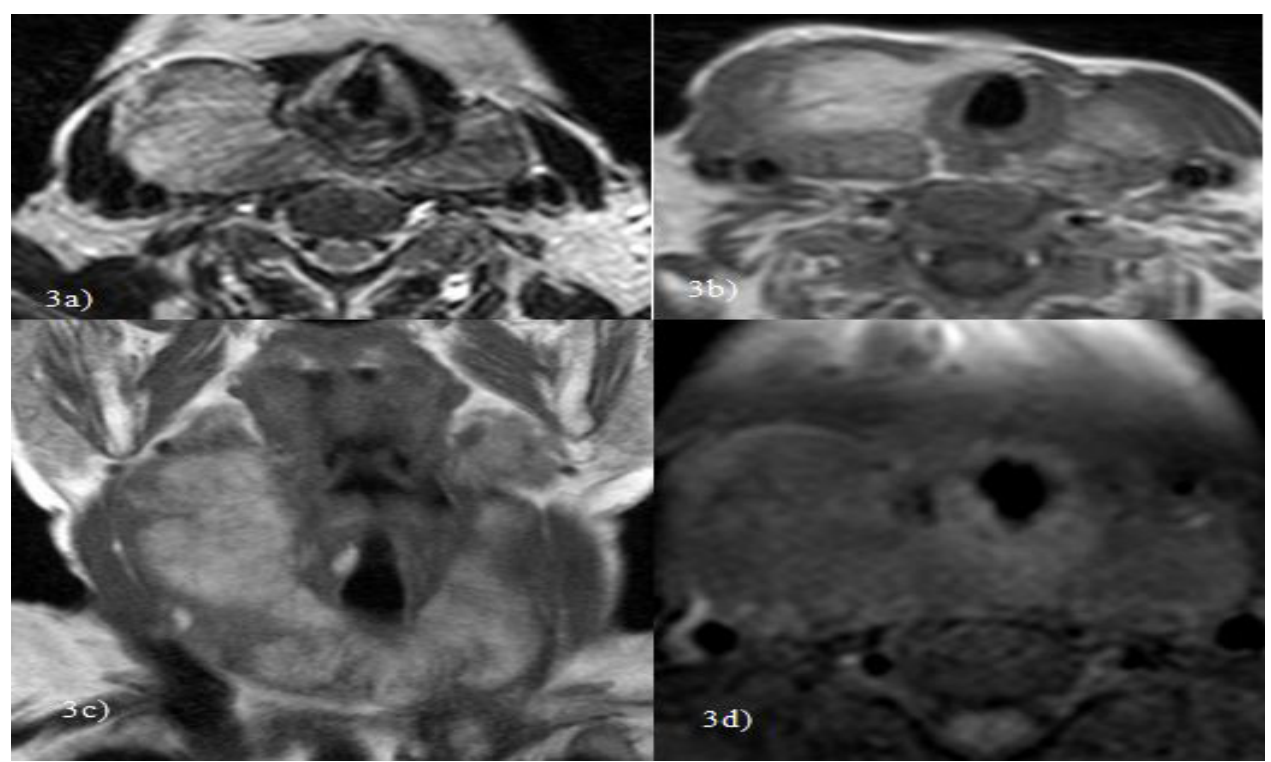

Figure 3: MR scan of neck. Axial $T 2 W$ 3a., axial $T 1 W$ 3b. and coronal $T 1 W 3$ c. shows thyroid glandular enlargement with intraglandular hyperintense lesion (isointense with subcutaneous fat) with linear hypointense strands within. Axial $T 1 W$ fat-suppressed 3d. shows suppression of hyperintense signal consistent with fatty nature of the lesion.

Fine Needle Aspiration Cytology (FNAC) of this thyroid lesion was done. Smears showed presence of benign looking thyroid follicular cells interspersed with fat and colloid. These cytological features were in concordance with the radiological diagnosis of thyrolipoma
(Figure 4). The patient underwent total thyroidectomy and the histological examination of the specimen confirmed the preoperative diagnosis of thyrolipoma. The patient is on regular follow-up and is doing well with no signs of any recurrence. 


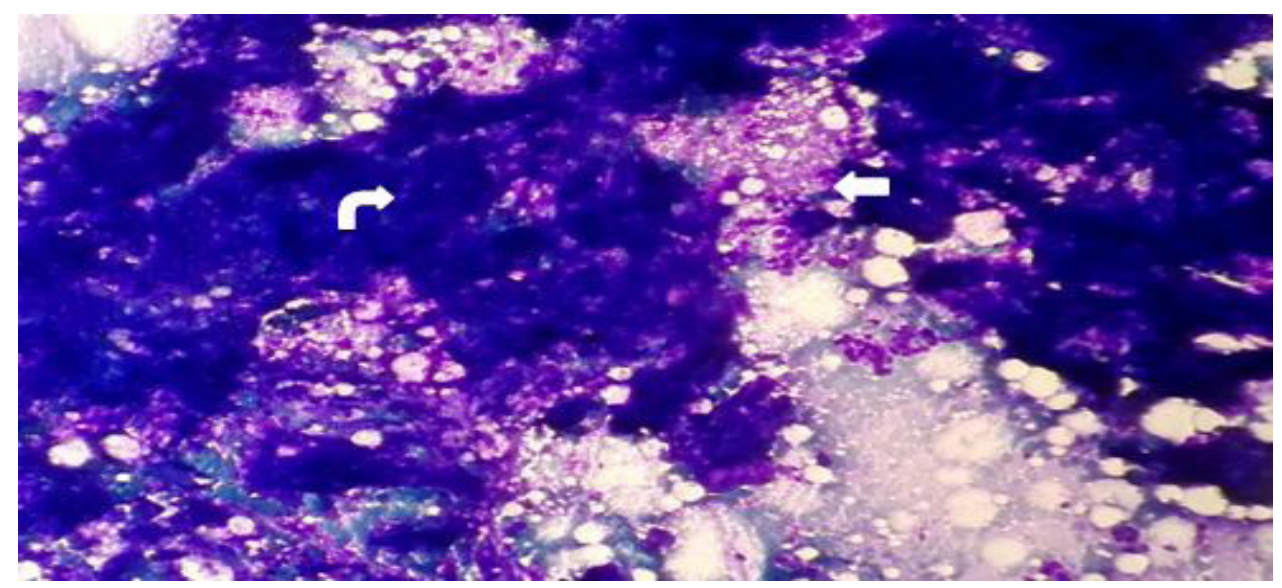

Figure 4: Microphotograph showing thyroid follicular cells (straight arrow) intermingled with fat fragments (bent arrow) (Giemsa stain, x 200).

\section{DISCUSSION}

Presence of fat in the thyroid gland is a rare finding. According to the pertinent world literature, there are mainly two theories behind the origin of adipose tissue within the thyroid gland. Few authors have proposed that the adipose tissue rests are incorporated in the thyroid gland during embryogenesis and proliferation of fatty tissue results in thyrolipoma, while other authors suggest metaplastic origin from fibroblasts. Small amounts of adipose tissue may be rarely seen in normal thyroid glands adjacent to the capsule, vessels, or in connective tissue septa. $^{2,3}$

Fat-containing lesions of the thyroid gland are broadly categorized as (a) lesions containing macroscopic fatty tissue and (b) lesions rich in microscopic intracellular fat vacuoles, referred to as clear cell or lipid-rich neoplasms. ${ }^{4,5}$ Cervical lipomas may appear as fatty nodules of the thyroid gland if they grow into the thyroid gland, multiplanar reconstructions can be used to resolve this issue in most cases. ${ }^{6}$ Thyrolipoma, thyrolipomatosis, lipomatous goiter, amyloid goiter, lymphocytic thyroiditis, Grave's disease, adenolipoma, intrathyroid parathyroid lipoma or thymic lipoma, encapsulated papillary carcinoma, and liposarcoma contain mixed fat and thyroid tissue. Thyrolipoma is a well-circumscribed encapsulated follicular adenoma of the thyroid gland which contains adipocytes; whereas, thyrolipomatosis usually presents at an earlier age as a diffusely enlarged thyroid and is marked by diffuse infiltration of adipose tissue in the thyroid stroma rather than a single focus with no evidence of encapsulation. Intrathyroid thymic and parathyroid lipoma usually present as a nodular unilateral lesion. According to Ge Y et al. ${ }^{7}$ in patients with extrathyroidal nodules and positive parathyroid scans, parathyroid lipoma is an important differential diagnosis of thyrolipoma. In these cases, the presence of cytoplasmic glycogen and positive immunostaining for parathormone supports the parathyroid tissue while positive thyroglobulin immunostaining indicates the thyroid tissue. ${ }^{8}$ Diffuse fatty infiltration of the thyroid gland is seen in lipomatous and amyloid goiters. ${ }^{9}$ Additionally, lipomatous goiters (also known as adenolipomatosis or choristomatous adiposity) usually manifest in patients at an earlier age as a diffuse swelling of the thyroid gland, whereas amyloid goiter is always associated with systemic amyloidosis and can be easily diagnosed by Congo red or crystal violent staining. ${ }^{5}$ Lymphocytic thyroiditis is a diffuse inflammatory process with presence of antithyroid antibodies. Grave's disease can be excluded on the basis of the normal thyroid function tests. Several thyroid gland neoplasms can also contain fat. The diagnosis of papillary carcinomas of the thyroid gland with a substantial amount of 
fatty tissue is very rare with only a handful of cases reported till date. Liposarcomas of the thyroid gland are also rare and present with rapidly growing masses and aggressive clinical features. ${ }^{10}$ Lipid-rich clear cell adenoma is characterized by massive steatosis of follicular cells with small round nuclei and foamy cytoplasm. Immunostaining for thyroglobulin is useful in such cases for identifying this cells. ${ }^{8}$

Preoperative FNAC also plays a pivotal role in differentiating all the thyroid lesions. ${ }^{11,12,13,14,15,16} \mathrm{Kim}$ HS et $\mathrm{al}^{17}$ have emphasized that though the presence of adipose tissue is a common finding within the cytological specimens, especially in obese individuals or with inadequate sampling. However, a high index of suspicion for thyrolipoma should be kept if an excess amount of adipose tissue is present in the submitted sample.

The current patient had diffuse enlargement of the thyroid gland. Her condition was euthyroid, and no enlarged lymph nodes or clinical signs of malignancy were found. Though her clinical and USG findings were not diagnostic of thyrolipoma however, the CT, MRI, FNAC findings were quite accurate in picking up the lesion which was further confirmed on histopathology of the resected specimen.

\section{CONCLUSION}

Nodules of the thyroid gland that contain macroscopic fat can be both non-neoplastic and neoplastic in nature and should always be kept in mind while dealing with thyroid gland swellings. The presence of macroscopic fat within the thyroid gland can be easily detected by radiological techniques especially $\mathrm{CT}$, and MRI, and this finding considerably limits the diagnostic possibilities. However, fatty tissue infiltration or fatty masses may be iso-echoic and most of the times cannot be differentiated from normal thyroid gland on USG. Thyroid profile of the patients and FNAC which is a simple and a cost-effective tool, can be used in pre-operative diagnosis of such lesions. Nevertheless, a definite diagnosis is usually made on histopathology as there are varieties of fat containing thyroid gland lesions which may evade the detection on radiology and cytology leading to diagnostic dilemmas and a therapeutic challenge.

\section{CONFLICT OF INTEREST}

None

\section{SOURCES OF FUNDING}

None

\section{REFERENCES}

1. Gupta A, Mathur SK, Batra C, Gupta A. Adenolipoma of the thyroid gland. Indian $J$ Pathol Microbiol 2008;51(4):521-522. https://doi.org/10.4103/0377-4929.43747

2. Kitagawa W, Kameyama K, Tamai S et al. Adenolipoma of the thyroid gland: report of a case. Surg Today 2004;34(7):593-596. https://doi.org/10.1007/s00595-0042772-y

3. Rosai J, Carcangiu ML, DeLellis RA. Tumors of the thyroid gland. In: Atlas of Tumor Pathology. Third series. Fascicle 5.Washington DC: $A m$ $J$ Surg Pathol 1994:172(3).83-193. https://doi.org/10.1002/path.1711710319

4. LiVolsi VA. Unusual tumors and tumorlike conditions of the thyroid. Surgical pathology of the thyroid. Major problems in pathology series 1990;22:323-350.

5. Schroder S, Bocker W. Lipomatous lesions of the thyroid gland: a review. Appl Pathol 1985;3(3):140-149. Available from: https://www.ncbi.nlm. nih.gov/pubmed/3842076 [Accessed 27th March 2019]. 
6. Leonidas JR, Goldman JM, Wheeler MF. Cervical lipomas masquerading as thyroid nodules. JAMA 1985;253(10):1436-1437. https:// doi.org/10.1001/ jama.1985.03350340088023

7. Ge Y, Luna MA, Cowan DF, Truong LD, Ayala AG. Thyrolipoma and thyrolipomatosis: 5 case reports and historical review of the literature. Ann Diagn Pathol 2009;13(6):384-389. https://doi.org/10.1016/j.anndiagpath.2009.08.003

Kadivar M, Kheirkhah Rahimabad P, Salarinejad S. Prominent Cold Nodule in Multinodular Goiter Revealed to Be Thyrolipoma: A Case Report. Iran $J$ Pathol 2016;11(5):456-459. Available from: https://www.ncbi.nlm. nih.gov/pubmed/28974966 [Accessed 26th March 2019].

8. Arslan A, Alic B, Uzunlar AK, Buyukbayram H, Sari I. Diffuse lipomatosis of the thyroid gland. Auris Nasus Larynx 1999;26(2):213-215. https://doi.org/10.1016/S03858146(98)00049-2

9. Andrion A, Gaglio A, Dogliani N, Bosco E, Mazzucco G. Liposarcoma of the thyroid gland: fine-needle aspiration cytology, immunohistology, and ultrastructure. Am J Clin Pathol 1991;95(5):675-679. https://doi.org/10.1093/ajcp/95.5.675

10. Demirpolat G, Guney B, Savas R, Tuncay G, Alper H, Sener RN. Radiologic and cytologic findings in a case of thyrolipoma. AJNR Am J Neuroradiol 2002;23(10):1640-1641. Available form: https://pdfs.semanticscholar.org/0b9f/48a7868e 55fac49f7c 7 37a3ba4c1f3c29b9b.pdf [Accessed 3rd April 2019].
11. DumanA. Thyrolipoma:Arare lesion of the thyroidgland.ODUJMed 2015;2:e17-e20. Available from: https://dergipark.org.tr/ download/article-file/150830 [Accessed 5th April 2019].

12. Bhasin T, Mannan R, Manjari M et al. Reproducibility of 'the Bethesda system for reporting thyroid cytopathology': A multicenter study with review of the literature. $J$ Clin Diagn Res 2013;7(6):1051-1054. https://doi.org/10.7860/ JCDR/2013/5754.3087

13. Sharma S, Mandal D, Yadav AK, Mandal AK. Primary thyroid lymphoma: a comprehensive summary of two cases. Int J Sci Rep 2015;1(3):177-180. Available from: https://www.scirep.com/ index.php/scirep/article/view/54 [Accessed 15th April 2019].

14. Mannan R, Piplani S, Sharma S, Manjari M, Gupta S. Cytological correlation of spectrum of head and neck lesions with epidemiological and diagnostic parameters. Indian J Pathol Oncol 2017;4(1):92-97. Available from: http://10.0.71.55/2394$\underline{6792.2017 .0018}$ [Accessed 15th April 2019].

15. Kaur J, Sharma S, Bhasin TS, Agarwal R, Mannan R. A rare incidental case of an occult breast carcinoma micrometastasis in papillary thyroid carcinoma: A view within a view. Thyroid Res Pract 2018;15(3):142-146. https://doi.org/10.4103/trp.trp_29 18

16. Kim HS, Yun KJ. Adenolipoma of the thyroid gland: report of a case with diagnosis by fine-needle aspiration cytology. Diagn Cytopathol 2008;36(4):253-256. https://doi.org/10.1002/dc.20666 